\title{
SEXTA MESA REDONDA
}

Profesor Di Paola: - ¿Qué técnica emplea para la conización del cuello?

Doctor Di Paola: —La más sencilla de todas es la extirpación del cuello con un bisturí, como se ha visto en las fotografías del fragmento extirpado. En este momento estamos tratando de probar no hacer sutura, porque la conización del cuello, que puede ser muy fácil cuando hay prolapso, puede ser muy difícil cuando el cuello está alto y la mujer es joven o por ejemplo en la nulípara. Estamos ensayando una técnica, que hasta ahora no ha presentado inconveniente. Se hace la conización y después un taponamiento. Pero en realidad nosotros aconsejamos y enseñamos la conización que se hace colocando los puntos clásicos del tumor en la parte anterior y posterior.

- ¿Qué conducta sigue usted, doctor Di Paola, ante un caso de citología positiva y biopsia de exocérvix y endocérvix por microlegrado con resultados negativos?

Doctor Di Paola: _En primer lugar nunca hacemos una biopsia por microlegrado para investigar un cáncer. En segundo lugar, si haciendo un legrado completo del cuello, del endometric con cureta, es negativo, tenemos la obligación de sospechar bien un carcinoma de la trompa o un carcinoma del ovario, como hemos tenido algunos casos, que hay que investigar sistemáticamente.

Al doctor Di Paola: - ¿Cómo explica las invasiones de la cúpula vaginal por el carcinoma intraepitelial no invasor?

Doctor Di Paola: - Pues muy senci1lo, el epitelio vaginal es igual al epitelio del cérvix. Entonces la invasión se hace por continuidad generalmente, y es una complicación muy peligrosa que hay que investigar siempre, no solamente en el carcinoma intraepitelial sino en el del primer estadio, porque muchas veces la lesión parece pequeñita, el cirujano, por economizarse unos minutos, extirpa sólo una poca cantidad de vagina sin investigar a fondo si hay propagación vaginal. Esa es la causa de muchas recidivas en el muñón vaginal. La propagación por dentro del epitelio hacia la vagina es muy frecuente. Tan así es que las primeras descripciones de carcinoma intra-epitelial las hizo en 1812 en Viena German Schottlander alrededor de los inter-carcinomas, que era la manera como él creía que se propagaban. Parece ser que no sólo se propaga así sino que se había originado en esa forma de carcinoma intra-epite- 
lial y había adoptado la forma invasora en la parte central, que era la única que se interpretaba en aquella época. De modo que la propagación por dentro del epitelio a la vagina tiene una importancia extraordinaria. Estamos absolutamente seguros de que esos seis casos que ha publicado nuestro querido amigo el profesor Pelín, de hace unos cuantos años, en el American Journal, de casos de carcinoma intraepitelial que les habían hecho histerectomía simple y que habían recidivado en la vagina, eran por esa circunstancia. Y el mismo doctor Howard Jones nos confesó después que desde entonces hacían lobulización siempre en todos los casos. Pero nosotros creemos que, mucho más científica, exacta y sencilla que la lobulización, es la exploración colposcópica de los fondos de saco en todos los casos de carcinoma intra-epitelial o de primer estadio, que aparentemente son circunscritos.

- ¿Qué experiencia tiene usted con la colpomicroscopia, y cómo compara sus resultados con los otros procedimientos?

Doctor Di Paola: -Ninguna, doctor.

Profesor: - ¿Qué experiencia tiene el equipo que usted dirige respecto de la prueba de sensibilidad y respuesta a las radiaciones ideadas por Ruth Graham?

Doctor Di Paola: -Bastante buena. Los resultados han sido publicados por el doctor Arturo Arrigui hace dos años en la Sociedad de Ginecología de Buenos Aires. Tenemos resultados actualmente que están de acuerdo con los obtenidos por los esposos Graham.
Actualmente hemos tenido que modificar un poco la técnica, debido a la modificación de la técnica en la aplicación del radium, haciéndola en dos etapas, pues hemos tenido algunas dificultades para establecer cuál es el momento más apropiado para hacer las tomas del material de vagina. Pero con la técnica clásica, los resultados que hemos obtenido están de acuerdo con los observados por los esposos Graham. Lamento no tener las cifras exactas, pero están publicadas en los boletines de 1960 de la Sociedad de Buenos Aires.

Profesor Di Paola: —¿Qué experiencia tiene en citología tumoral con el método de la fluorescencia y qué ventaja tiene sobre el Papanicolau?

Doctor Di Paola: -No tenemos experiencia.

- Profesor Di Paola, ¿cuál es la conducta terapéutica a seguir en el carcinoma intra-epitelial?

Doctor Di Paola: -Al principio, como casi todos los ginecólogos, impresionados por el nombre de carcinoma, hacíamos el tratamiento del cáncer. Pero a medida que se fue discutiendo más el problema y conociéndolo mejor por medio del análisis de los casos, vimos cómo lo habían hecho ya en otros centros muy importantes de diferentes países, que nos estábamos pasando en la intensidad del tratamiento. Como hacer una operación de este tipo es bastante difícil y al no quedar bien hecha puede traer trastornos como se vio ayer con el relato de fístulas urinarias, entonces ahora nos concretamos a hacer 
una conización. Si la conización no demuestra que hay carcinoma invasor, porque muchas veces en el lugar donde se ha hecho la biopsia, donde estaba la lesión colposcópica, hay un carcinoma intra-epitelial. Pero más arriba o más abajo puede haber un carcinoma invasor; es un proceso que tardará ocho o nueve años, pero que hay que tener en cuenta, que esa es la evolución natural de la enfermedad. Es por eso por lo que no nos conformamos con la biopsia, sino que hacemos también la conización, llegando hasta el orificio interno y estudiando toda la pieza. Si comprobamos que no existe el carcinoma invasor en todo el epitelio cervical, consideramos el tratamiento terminado, lo mismo que si se comprueba que el corte quirúrgico ha pasado por fuera de los límites de la lesión intra-epitelial. Dejamos a la enferma entonces en observación, salvo tres excepciones: $\mathrm{Si}$ la enferma proviene de centro o localidad muy alejada de la ciudad, sabemos que no va a volver especialmente para hacerse examinar, entonces hacemos una histerectomía. Otro caso de excepción es cuando la enferma tiene una patología agregada: mioma, anexitis o cualquier otra lesión; entonces también hacemos histerectomía. En los demás casos nos quedamos con la conización y observación de la enferma. Hasta ahora no hemos tenido ninguna recidiva.

Al profesor Di Paola: - ¿Existe alguna dificultad para el estudio histológico del cono obtenido con el conizador eléctrico o prefiere usted la muestra obtenida en frío?
Doctor Di Paola: —Nuestro patólogo prefiere la muestra obtenida con el bisturí en frío.

Al profesor Di Paola: - ¿En qué casos están indicados siempre los cortes seriados?

Doctor Di Paola: - Nosotros hacemos siempre cortes semiseriados, porque por razones financieras nos es absolutamente imposible hacer cortes seriados; no tenemos ni el tiempo ni el personal para gastarlo en estos cortes seriados, que sería lo indicado en todos los casos.

Al profesor Di Paola: - Diagnóstico diferencial histológico entre la hiperplasia típica del exocérvix y carcinoma intra-epitelial.

Doctor Di Paola: -Para que se considere que existe un carcinoma intraepitelial tiene que aparecer toda una serie nueva de células que antes no existían en el organismo, es decir, tiene que haber una atipia completa. Las células del cuerpo espinoso no tienen que tener puentes inter-celulares, tiene que haber alteraciones en el núcleo, mitosis en toda la altura del epitelio, alteración en la disposición de la arquitectura epitelial; es decir, que tiene que haber alteraciones celulares e histológicas que indiquen que una cepa atípica de células carcinomatosas ha aparecido.

En cambio, en la hiperplasia se observan ciertas alteraciones que demuestran un estímulo anormal, que sólo se manifiesta en las capas profundas del epitelio. Las alteraciones no son tan 
llamativas; las mitosis no son tan acentuadas; la disposición de las células no es tan atípica; la impresión visual del patólogo es de fundamental importancia en este problema, y es muy difícil que un patólogo escriba exactamente y en detalle el diagnóstico que hace en base a una serie de pequeñas cosas, lo cual hace que se incline hacia un lado u otro. Pero lo esencial es que la hiperplasia es un epitelio anómalo no atípico, y el carcinoma inter-epitelial es un epitelio atípico.

Profesor Di Paola: — ¿Cuál es la utilidad de la toma endometrial para uso citológico?
Doctor Di Paola: _La toma endometrial da resultados o porcentajes bastante menos elevados que las tomas vaginales o cervicales. En realidad habría que hacer siempre una toma dentro del canal. Esta es una maniobra complicada y difícil de hacer; por lo tanto es imposible hacerla en forma seriada y en grandes números como en las lesiones cervicales. Nosotros hacemos esta toma cuando sospechamos que hay carcinoma endometrial; pero en general preferimos para el endometrio el clásico raspado explorador, por ahora insustituíble a mi modo de ver. 